\title{
Devenir-democrático frente a la sociedad de control
}

\section{The democratic future in front of the control society}

ARTÍCULO

\author{
Darío Damián Peralta \\ Universidad Nacional de General Sarmiento, Argentina. \\ Contacto: dperalta@cap.uvq.edu.ar
}

Recibido: agosto de 2017

Aceptado: noviembre de 2017

\begin{abstract}
Resumen
El presente artículo realiza una reflexión sobre la posibilidad de pensar la filosofía política de Gilles Deleuze y su relación con la democracia. Se defiende el concepto de devenirdemocrático como una herramienta eficaz para sostener una crítica filosófica y una militancia política frente al sistema capitalista, y su expresión más actual, la sociedad de control. Primero, se realiza un análisis crítico de dos autores (Philippe Mengue y Paul Patton) que examinan los límites y los principios de una política democrática en Deleuze. Luego, se promueve una comprensión de la democracia a partir de tres conceptos deleuzianos. La democracia es entendida como un rizoma, como un devenir revolucionario y minoritario, y como una máquina de guerra.

Palabras claves: devenir-democrático; axiomática capitalista; sociedad de control; rizoma; devenir-revolucionario; máquina de guerra.

Abstract

The present article makes a reflection on the possibility of thinking to the political philosophy of Gilles Deleuze and its relation with the democracy. The concept of becoming-democratic is defended as an effective tool to sustain a philosophical criticism and a political militancy in front of the capitalist system, and its most current expression, the control society. First, a critical analysis is made of two authors (Philippe Mengueand Paul Patton) who examine the limits and principles of a democratic politics in Deleuze. Then, an understanding of democracy is promoted from three Deleuzian concepts. Democracy is understood as a rhizome, as a revolutionary and minority becoming, and as a war machine.
\end{abstract}

Keywords: Becoming-democratic; capitalist axiomatic; control society; rhizome; becomingrevolutionary; war machine.

\section{Introducción}

El presente texto tiene como objetivo explicar la concepción de democracia en Gilles Deleuze, cuál es el lugar que ocupa en su ontología política y cómo se opone a la democracia liberal en su relación con el capitalismo y la sociedad de control. En primer término, para una filosofía deleuziana, la democracia tiene el potencial de ser configurada como un rizoma. Esto significa que debe ser entendida como una nueva imagen del pensamiento político, ya que posibilita una serie de conexiones heterogéneas (Deleuze y 
Guattari [en adelante $D+G$ ], 2002; p. 13). Lo cual permite configurar un activismo político que retoma del presente sólo lo que es afirmado (Deleuze, 1998, p. 106), es decir, que se afirma como un devenir activo (Deleuze, 1998, p. 31). Se estudiarán tres lineamientos específicos de esta política deleuziana en el que se despliega la democracia y se configura como un rizoma.

(i) La democracia es una nueva imagen del pensamiento, signada por su potencial de criticidad frente a las formas concretas del poder social dominante, en particular frente a la sociedad de control. Gracias a la afirmación diferencial, la democracia deviene un movimiento.

(ii) La democracia es un devenir-revolucionario y minoritario, como tal se opone a las segmentaciones molares que se configuran como bloques mayoritarios. En tanto que devenir-activo, el devenir-democrático requiere conectarse con el devenir-revolucionario y el devenir-minoritario. A la vez, en tanto que devenir, es un acontecimiento político, que se opone al presente entendido como status quo, y a la historia entendida como agenciamiento discursivo y material planificado por fracciones dominantes en el sistema del poder social.

(iii) La democracia es una máquina de guerra que se opone al Estado, aunque requiere de instituciones que potencien las multiplicidades y los procesos de diferenciación intensiva. Sólo aceptará instituciones que afirmen la democracia como revolución permanente.

Estas caracterizaciones sólo describen tres conexiones que la democracia como sistema abierto del pensamiento (es decir, como rizoma), posee en términos virtuales. Ciertamente la filosofía política deleuziana puede llegar a efectuar otras conexiones, ello depende de su pasaje a condiciones existenciales concretas. Y dado el estado actual de cosas, el devenir-democrático sólo puede acaecer como una contra-efectuación (Deleuze, 1994, p. 131), una contra-hegemonía, una contra-cultura frente a los poderes constituidos. La democracia revolucionaria es el pensamiento más poderoso para enfrentar al sistema capitalista y la sociedad de control.

Además, se revisarán dos investigaciones que profundizan esta temática. Las interpretaciones críticas de $\mathrm{P}$. Mengue impelen a la pregunta en qué medida la política democrática es compatible con la ontología deleuziana. Mientras que P. Patton ha escrito una serie de textos donde se opone a la postura de Mengue y defiende la idea de un giro hacia el pensamiento democrático en la última etapa de la filosofía de Deleuze.

Por último, se problematiza la organización del Estado como aparato de captura, su relación con el devenir-minoritario, la función de autonomía y la revolución molecular.

\section{El caso Mengue.}

La primera interpretación a despejar es aquella según la cual Deleuze defendería una política aristocrática y anti-democrática (Hallward, 2006; Zizek, 2006; Mengue, 2003). Sin embargo, desde sus primeros textos [1955] se observa una defensa de la institucionalidad 
democrática: "una tiranía es un régimen en el que hay muchas leyes y pocas instituciones, mientras que la democracia es un régimen en el que hay muchas instituciones y muy pocas leyes" (Deleuze, 2005b, p. 75). Esta idea es ratificada [en 1967] cuando estudia la relación entre Louis de Saint-Just y el Marqués de Sade, ambos defienden la institucionalidad de la república. "Más leyes cuantas menos instituciones (monarquía y despotismo), más instituciones cuantas menos leyes (república)" (Deleuze, 2001, p. 82). EI ideal político del Marqués de Sade sería un sistema de instituciones sin leyes, puesto que éstas inmovilizan la vida socio-política, dado su carácter de prohibitivas. Para Sade, una república con instituciones sin leyes sería un estado de revolución permanente y de movimiento perpetuo (Deleuze, 2001, p. 82).

Por otra parte, si la filosofía política deleuziana sostuviera una primacía de la desterritorialización (Mengue, 2008a, p. 130) en efecto, el problema sería cómo configurar una formación social con un mínimo de estabilidad. Pero en Deleuze, la afirmación política de potenciar las fuerzas creativas no conduce a criticar toda formación política estable. Si bien las líneas de fuga tienden a escapar y hacer escapar los flujos capturados en los segmentos molares, lo que se da allí es una diferenciación en el uso y direccionamiento de las singularidades puestas en juego. Deleuze [en 1953] sostiene la distinción entre aquellas herramientas políticas que permiten afirmar la potenciación de fuerzas creativas de aquellas que obstaculizan su ejercicio (Patton, 2010, p. 15). Las instituciones, a diferencia de las leyes, son modelos de acción. "La institución no es una ilimitación como la ley, sino, por el contrario, un modelo de acciones, una verdadera empresa, un sistema inventado de medios positivos, una invención positiva de medios indirectos" (Deleuze, 1977, p. 42).

Por ello mismo, a la noción de "modelo" se le criticará sólo cuando esté asociada a funciones de calco, es decir, de una copia en relación a un principio trascendente, a una repetición sin diferencia. "Hacer el mapa y no el calco" (D+G, 2002, p. 17). Por lo tanto, el rizoma democrático es un modelo de acción que afirma la potenciación de fuerzas creativas. La desterritorialización no se realiza simplemente en función de destruir una segmentación molar, ahí sólo se contempla un movimiento negativo. Por el contrario, la desterritorialización se realiza en función de crear y fortalecer un plano de consistencia, y sobre este plano se configuran todo tipo de segmentos. De allí, la preocupación por las unidades de medida para los estratos, los lineamientos, incluso para el $\mathrm{CsO} .{ }^{1}$ En fin, la consistencia ofrece una unidad de sentido. La filosofía política deleuziana no se opone a todo tipo de ordenamiento social, sino a aquellos modelos nihilistas donde triunfan las fuerzas y los valores reactivos, tales como el fascismo, el capitalismo y el estalinismo ( $D+G, 1998$, p. 65).

\footnotetext{
${ }^{1}$ Se refiere a: "Los estratómetros, los deleómetros, las unidades CsO de densidad, las unidades CsO de convergencia" (D+G, 2002, p. 10).
} 
Ahora bien, un rasgo de una política deleuziana es la ausencia de un sujeto histórico, y sin embargo se promueve la emergencia de un pueblo que falta. El concepto de multiplicidad para el campo de la filosofía práctica debe implicar el rechazo al individualismo y al atomismo social, y por ello mismo, debe involucrar a su vez algún tipo de relación social consistente. Una relación social en apertura y movimiento constante, sin jerarquías y sin totalización, que "conecta rizomaticamente" (Mengue, 2008b, p. 2019). El pueblo tiene el potencial de emerger como multiplicidad socio-política. No se trata de entender al pueblo como entidad ontológica, como sustancia o como sujeto histórico. El pueblo ha de emerger como acontecimiento revolucionario en cuanto que una multitud que se expresa como diferencia intensiva y que se opone al imperio (Negri \& Hardt, 2004). En los estudios sobre Spinoza, Deleuze afirma que en el contrato cada hombre renuncia a su potencia para formar un todo (la ciudad o Estado), pero además es necesario un asentimiento colectivo a una determinada forma de Estado, siendo el sistema democrático el que permite sustituir al temor por una afección positiva, esto es, la amistad o amor por la libertad (Deleuze, 1996, p. 258; 2001b, p. 132).

Ahora bien, esto puede llegar a ser comprendido como un realismo político, es decir, la posición política de una inmanencia radical conduciría a un modelo de Estado maquiavélico (Mengue, 2006, p. 18), ¿es aplicable? (Mengue, 2007, p. 173). Y si bien es necesario renunciar a fundar moralmente el Estado, de ello no se deduce que los presupuestos de la teoría de Maquiavelo encajen en la política deleuziana. No es posible sostener una discontinuidad entre ética y política; no es necesario aceptar una inmanencia fallida o discontinua (Mengue, 2006, p. 25), pero sí una diferencia entre moral y una éticapolítica propiamente spinoziana (Deleuze, 2001b, p. 27). Para ello es necesario pensar que la ética spinoziana conduce a la práctica política, y que sin ésta carece de todo sentido.

Además, es necesario recordar que el concepto de "pueblo" ha sido manipulado durante el siglo XX por la extrema derecha, en particular por la propaganda nazi (Mengue, $2008 b$, p. 220). Ciertamente, la noción de deutsches volk tenía un doble impulso, hacia el interior conducía a la búsqueda de una raza pura, y hacia el exterior, a la expansión territorial. No obstante, la noción de pueblo ha sido promovida por la teoría republicana clásica. ${ }^{2}$ Esta tradición -relegada por Mengue-, asevera que sólo puede haber pueblo si hay un derecho común. Hay una identidad entre pueblo y ciudad, el derecho remite a la utilidad

\footnotetext{
${ }^{2}$ Según San Agustín, la república remite al pueblo, siendo éste "una junta compuesta de muchos, unida con el consentimiento del derecho y la participación de la utilidad común" (Agustín, 1965, p. 606). Cicerón afirma que Dios recompensará a los que favorecen a la República entendida como "Concilia coetus hominum iure sociat" (Cicerón, 1992, p. 132).
} 
común reconocida por la razón (D’ors, 1992, p. 21). Tal idea coincide con la política spinoziana. $^{3}$

Ahora bien, las razones aducidas por Mengue resultan evidentes, es necesario diferenciar el concepto deleuziano de aquella raíz ultra-nacionalista, ligada al pensamiento fascista. Mengue señala respecto a Deleuze: "sus propias ideas sobre este tema son directamente opuestas a este concepto, que se esfuerza por deconstruir" (Mengue, 2008, p. 221). La noción deleuziana de pueblo es entendida como algo que falta y debe ser creado. Por este motivo, se conecta inmediatamente a la de fabulación. De nuevo, Mengue realiza una serie de cuestionamientos:

a) dado que la idea de un pueblo es tomada de Kafka, considera que toda filosofía política se reduce a un esteticismo.

b) el pueblo como algo que es buscado, puede ligarse a una concepción negativa del deseo, una falta, un objeto a -en términos lacanianos. El pueblo no puede permanecer como virtual, debe hallarse en un contenido histórico actual.

c) Además de una dimensión filosófica y artística del pensamiento, ha de haber un lineamiento político específico, al que denomina plano doxico ${ }^{4}$ (Mengue, 2008, p. 235).

Frente a esto, se realizará una serie de críticas a la interpretación de Mengue:

(a) Si bien existe una relación entre literaria y política, ésta no se reduce a una teoría del arte, a un movimiento o tendencia estética. La literatura menor no tiene como objeto o como finalidad la promoción del esteticismo, sino la creación de líneas de fuga y el empoderamiento de los grupos socio-culturales minoritarios. La literatura es un asunto de las minorías, y en cuanto tal, ya es un agenciamiento colectivo y político. ${ }^{5}$

(b) La falta sólo puede ser negativa si y sólo si es considerada como una casilla vacía dentro de un sistema estructural. En cambio, la democracia que se busca es pensada como una potencia virtual. La virtualidad es tan real y maquínica como cualquier efectuación conducente a un estado de cosas actual. Un positivismo extremo que sólo

\footnotetext{
${ }^{3}$ Según Spinoza: "Este derecho que se define por el poder de la multitud, suele denominarse Estado. Posee este derecho, sin restricción alguna, quien, por unánime acuerdo, está encargado de los asuntos públicos" (Spinoza, 1986, p. 94)

${ }^{4}$ La distinción propuesta por Mengue remite a la división que ya había propuesto Badiou, quien afirma cuatro figuras o bucles, entendidos como funciones genéricas (científica, artística, dóxica y amorosa) $(D+G, 1995$, p. 152). El plano dóxico corresponde a la política entendida como el ámbito para la discusión y la confirmación del sentido común ( $D+G, 1995)$, advierten que desde el período clásico, se vincula a la filosofía con un debate entre amigos dado en un simposio, que ni siquiera Platón ha podido revertir (D+G, 1995, p. 138).

${ }^{5}$ No es una nimiedad pretender que el retorno del esteticismo de la política reconduce al uso pregonado por el nazismo del arte. Walter Benjamin afirma: "Este es el esteticismo de la política que el fascismo propugna. El comunismo le contesta con la politización del arte" (Benjamin, 1989, p. 127). La posición deleuziana no coincide a pie puntillas con Benjamin, cuando aquél afirma que el cine es un arte masivo, pero no democrático (Deleuze, 2005a, p. 287). Para Benjamín con el cine se advierte la tensión entre fuerzas de trabajo y desarrollo técnico. El cine "enseña que la servidumbre al servicio del mismo sólo será sustituida por la liberación mediante el mismo cuando la constitución de lo humano se haya adaptado a las nuevas fuerzas productivas inauguradas por la segunda técnica" (Benjamin, 1989, p. 57).
} 
acepta la pura actualidad impediría la chance del advenimiento revolucionario. Sin virtualidad no hay diferenciación intensiva y promoción de nuevas multiplicidades políticas.

(c) Para Deleuze, la filosofía no radica en el debate, sino en la producción de conceptos. Sólo puede haber crítica filosófica en la medida en que se diferencia de la doxa. Esto no conduce a una alianza con la episteme platónica. El platonismo instaura un Uno trascendente que se superpone sobre la univocidad del ser ( $D+G, 1995$, p. 48). Para Deleuze, el pensamiento se opone a la doxa, al caos y a la trascendencia. El pensamiento deleuziano se construye bajo un dispositivo rizomático en un plano de inmanencia.

\section{Lo político deleuziano.}

Tanto la forma-Estado como la noción de máquina de guerra son máquinas abstractas, que serán actualizadas según las condiciones materiales en cada caso (Patton, 2013, p. 156). Lo cierto es que la filosofía deleuziana posee una vocación política (Patton, 2008). La tarea de la filosofía es crear conceptos que permitan establecer una crítica al estado de cosas dominante, y que fortalezca la lucha contra el capitalismo. El postulado de Patton sostiene que la última etapa de la obra deleuziana se caracteriza por un giro hacia la defensa de un pensamiento democrático. No se renuncia a la revolución pero se distingue de cualquier proceso histórico revolucionario. A su vez, se diferencia de las democracias liberales dominantes y de sus contenidos institucionales específicos. El devenir democrático se halla unido a un devenir revolucionario, pero ambos permanecen en plano de la pura virtualidad. El devenir democrático es un principio normativo inmanente e indefinido que "apunta hacia formas futuras de democracia aún no realizadas, pero también nos recuerda que no existe una forma definitiva que llegue nunca" (Patton, 2008, p. 180).

La ontología política deleuziana determina una cierta orientación normativa que sustenta la prioridad del devenir minoritario frente a cualquier segmento mayoritario, pero no aparece como una ley externa al proceso, sino como un rasgo interno a la experimentación (Patton, 2008, p. 182). ¿En qué consiste el giro normativo deleuziano y cuáles son sus causas? Desde mediados de los 80 , Deleuze analizó tópicos propios del liberalismo político, tales como los derechos humanos. Su crítica concierne a rechazar la interpretación liberal de estos derechos y que sean interpretados como principios universales, es decir, como un valor trascendente. La declaración de derechos no surge como resultado de razonamientos deductivos, sino de la lucha y la inventiva en el campo de la jurisprudencia. Los derechos serían revalidados en la opinión pública donde los ciudadanos se expresaran libremente (Patton, 2008, p. 184).

El devenir-democrático no es simple y meramente un proyecto ético. Del mismo modo, pensar el Anti-edipo y Mil Mesetas como exposiciones de una ética del devenir, ética de los flujos o de las desterritorializaciones (Patton 2010, p. 136; 2007, p. 4) conlleva 
a tergiversar el sentido de la filosofía deleuziana: "pues, antes que el ser, está la política" $(D+G, 2002$, p. 207). Pero también, pensar que la distinción entre desterritorialización positiva y negativa expresa el ideal normativo de la ética deleuziana (Patton, 2007, p. 5) conduce a un segundo problema, a saber, "estas dos grandes formas de desterritorialización no mantienen una relación evolutiva simple" ( $D+G, 2002$, p. 518). Es decir, una línea de fuga puede conducir a una reterritorialización aún más profunda, pero al inicio de movimiento esto jamás puede ser percibido. La distinción entre lo positivo y lo negativo sólo es una respuesta a la pregunta ¿qué ha pasado? Ciertamente cada experimentación deja una enseñanza; en todo caso, para las reglas concreta los autores enfatizan la prudencia ( $D+G, 2002$, p. 513). Frente al interrogante ¿es esta una verdadera línea de fuga que conduzca a un nuevo agenciamiento revolucionario?, siempre se corre el peligro de estropear la desterritorialización. "Todo se juega en la mayor incertidumbre" (Deleuze \& Parnet, 1980, p. 166). Así mismo, pensar sólo en el futuro de la revolución, conduce a abandonar el devenir-revolucionario.

Por último, es relevante preguntar si es posible trazar un acercamiento entre la política normativa de Rawls y el devenir-democrático deleuziano (Patton, 2007, p. 12). La normativa rawlsiana descansa en la razón pública, la cual exige que cada ciudadano sea capaz de justificar sus decisiones políticas basándose en valores y normas públicamente disponibles, es decir desde una cultura política. Es difícil comprender en qué sentido, la política deleuziana estaría de acuerdo con estos postulados de justicia. Por el contrario, es posible ver, por lo menos, dos críticas a este acercamiento. Primero, Deleuze considera que la cultura política liberal es parte integral de la fabricación de miseria humana (Deleuze, 1995, p. 271). Mientras que su política promueve "líneas activas de fuga revolucionaria, líneas de descodificación absoluta que se oponen a la cultura" (Deleuze, 1995, p. 40). Segundo, el sujeto demócrata liberal es pensado por Rawls como un ser razonable, mientras que para Deleuze es un individuo disciplinado por agenciamientos de poder (D+G, 2002, p. 152). ${ }^{6}$

\section{Devenir-democrático y su diagrama rizomático.}

Para que la política democrática entre en un devenir-activo es preciso que se desarrolle en un plan de consistencia. Aquí se esbozan tres lineamientos de la diagramación del devenir-democrático.

\footnotetext{
${ }^{6}$ El disciplinamiento social en las democracias capitalistas tiene como parte de su aprendizaje, el autodominio de estos arrebatos. Además, el espacio público para el desarrollo de valores y normas razonables es el producto de una lucha por el poder social, es decir, es un lugar que ya ha sido conquistado por una mayoría. Dicho espacio nada tiene de razonable, pues allí sólo se impone el sentido común y el buen sentido (Deleuze, 2006, p. 186) que anulan toda posibilidad para el pensamiento crítico, para una cultura de la alegría (Deleuze, 1995, p. 14).
} 


\subsection{Democracia como imagen intempestiva del pensamiento. La democracia} griega tomaba el espacio público para debatir todo tipo de opiniones antagónicas y sólo por medio de la decisión de una mayoría calificada se alcanzaba la legitimidad de este fallo. ${ }^{7}$

Lo primero a observar es que Deleuze rechaza la imagen de la filosofía como un espacio para la "conversación democrática universal" (D+G, 1995, p. 33). La tarea del filósofo no es debatir sino crear conceptos. $Y$ estos conceptos no están al auxilio de las disputas políticas en las rivalidades públicas. Estos conceptos tienen la función de introducir un devenir-democrático en el contenido político de los acontecimientos históricos de cada sociedad. La creatividad filosófica está ligada directamente al pensamiento crítico. En este sentido, la filosofía no parece tener una utilidad, puesto que no está al servicio de generar un bien para el sistema capitalista, ni se arrodilla servilmente ante ningún poder constituido. Filosofar a martillazos permite ante todo la ruptura de la imagen del hombre unidimensional, y posibilita la apertura histórica a un devenir otro.

No obstante, la filosofía se ha visto constantemente amenazada por las condiciones materiales de existencia, y cada vez que ha recaído al servilismo ideológico de ponderar el sistema de explotación vigente sólo ha podido formular una imagen desvirtuada de su potencial. El último de sus avatares es verse envuelto en una competencia inesperada, la creatividad conceptual en la actualidad recae en manos de los medios de comunicación, en particular en el agente publicitario ( $D+G, 1995$, p. 100). ${ }^{8}$

De este modo, el publicista aparece en la sociedad posmoderna, como el agente creativo al servicio de grandes empresas comerciales. $\mathrm{Y}$ para que su exposición tenga eficacia se han montado enormes aparatos de resonancia que permiten reducir las maquinaciones del deseo al gesto pasivo del consumo. Quedan solapadas las síntesis de producción y de distribución ( $D+G, 2007$, p. 13). El fetichismo es la herramienta que posibilita la pervivencia del sujeto, en tanto apéndice de la máquina de deseo ( $D+G, 2007$, p. 28). En los mecanismos de comunicación, la información está atravesada por intereses de poder (Deleuze, 2012, p. 5) y las expresiones artísticas difícilmente puedan circular con libertad por estos circuitos de control. Una idea filosófica no tiene nada que ver con el orden de la comunicación. Trasmitir información no sólo es un acto de habla, sino un acto de dominación, constriñe a creer en lo que se informa. El publicista crea neologismos, los grupos sociales para convertirse en dominantes deben usar y manipular esos neologismos,

\footnotetext{
${ }^{7}$ El Agorá en su origen es un espacio circular donde se debate en público, todos en derredor son considerados iguales [isoi, homonioi], se dirigen hacia el centro [mesón] "para tomar la palabra y presentar su punto de vista" (Yamauchi, 2017, p. 44). Ezquerra afirma: "El verbo correspondiente a agorá es agoreúo, hablar en público. (...) Toda palabra pública funda comunidad al ser acción recíproca que involucra al hablante y al (o a los) oyente(s)" (Ezquerra Gómez, 2009, p. 35).

${ }^{8}$ Este personaje tan extraño a la filosofía se arroga el derecho de crear conceptos: "think different", "think green", "just do it", "imposible is nothing", "connecting people", "Shared, life is more", "ideas forlife". No se trata de frases sugestivas, muchos menos de un dato informativo, sino de un lenguaje imperativo formulado como una consigna $(D+G, 2002$, p. 81).
} 
es decir, generar el consumo como única forma de deseo social. Se anula con ello, la posibilidad de conectar el deseo y el pensamiento crítico. Este es un rasgo sobresaliente de las sociedades de control.

El control se caracteriza por una serie de innovaciones de los mecanismos de seguridad, frente a la crisis de las instituciones disciplinarias (Deleuze, 1995, p. 243). Ya no se ejerce únicamente una vigilancia en instituciones de encierro, sino que fundamentalmente la inventiva refiere a un control en espacios abiertos. Esto no remite de modo alguno a un progreso en la mentalidad liberal, por el contrario, "implica una serie de tecnologías de vigilancia policial o de corporaciones cuasi-estatales, a lo que se suma toda una serie de tarjetas de identificación y solicitudes de entrada de inmigrantes" (Protevi, 2009, p. 92).

Así podemos ver que (a) el poder disciplinario se encargaba de concentrar una serie de elementos heterogéneos y de sintetizar la multiplicidad de instituciones de encierro. Mientras que los dispositivos de seguridad configuran series abiertas en base a una ampliación constante del mercado capitalista a nivel mundial. (b) El poder disciplinante se encomendaba la tarea da realizar constantes exámenes y de inculcar una normativización de las conductas hasta el mínimo de los detalles (Deleuze, 1987, p. 114). Mientras que los mecanismo de seguridad gubernamental se guían por el imperativo de "dejar hacer", de no intervenir en los fenómenos sociales siempre que se mantenga un nivel estadístico aceptable para la vida social. (c) De lo anterior, se deduce que el poder disciplinario ejerce una codificación positiva, que convive con las leyes soberanas de orden prohibitivo, y con ello crea un espacio de convivencia artificial. Mientras que la seguridad gubernamental se comisiona la tarea de controles estadísticos, y con ello busca una regularidad bio-política ejercida sobre la población (Deleuze, 1987, p. 101).

Por su parte, W. Burroughs llama sociedad de control (Deleuze, 1985, p. 279) a aquella formación donde los dispositivos propios del totalitarismo son compaginados con los axiomas del sistema capitalista contemporáneo. Esta introducción se realiza de manera sutil, es decir, no se procura alterar la estructura de la macropolítca, ni el sistema democrático, ni su orden democrático. En el delirio del yonqui, el control se arraiga en el plano psíquico. "Los rusos están utilizando esta droga en experimentos sobre trabajo forzado. Pretenden inducir estados de obediencia automática y control de pensamiento, literal. El truco fundamental. Nada de aprendizaje, nada de rollos, tan sólo introducirse en el psiquismo de otro y dar órdenes" (Burroughs, 1984, p. 128).

Por otra parte, es posible ver que la resonancia proferida en los medios de comunicación es razón suficiente para considerar como verdadero hasta los enunciados que carecen del mayor rigor lógico. En el caso de Toni Negri, se lo acusa de terrorismo, ${ }^{9}$ primero se lo incrimina de ser parte activa, frente a ello se descubre que Negri estaba en Paris, y no

\footnotetext{
${ }^{9}$ Aldo Moro fue asesinado el 9 de mayo de 1978, Negri fue detenido el 7 de abril de 1979, inculpado de complicidad (Deleuze, 2007, p. 159).
} 
en Italia. Se cambia la acusación, entonces sería un conspirador, su ideólogo. Se investiga un supuesto llamado, se interpreta con mala fe sus escritos. $Y$ en la medida en que se refuta cada inculpación, se inventan nuevas hipótesis auxiliares, en un proceso que conduciría irremediablemente a un infinito absurdo. Deleuze critica el carácter ilógico de los alegatos acusatorios: si participó del secuestro sería culpable, pero si no participó sería tanto más responsable. Y aunque Negri en sus escritos se opone al terrorismo de las "brigadas rojas", eso no importa, tan sólo sería una fachada, en el fondo de su alma, es casi seguro que adhiere a ella, en todo caso es culpable (Deleuze, 2007, p. 160). El mecanismo se resume en que la acumulación de contradicciones y su resonancia en los mass-media convertirán por arte de magia a este fango de mentira en una verdad revelada. La crítica deleuziana se resume en que el principio de no-contradicción que ha servido de base para un juicio justo, ha sido abandonada por la lógica de los medios de comunicación, que se fundamentan en mecanismo de repetición sin diferencia: "¡Ya se trate de diarios o de semanarios, de periódicos o de emisoras de radio y televisión, su principio es el de acumulación" (Deleuze, 2007, p. 161). Lo único que interesa es el fulgurar del título de primera plana, "Ios desmentidos de la víspera no tienen influencia" (Deleuze, 2007, p. 161). El uso del condicional es la herramienta que convierte al periodismo en un acto inquisitorio, es decir, que se alimenta de su propia irracionalidad. En otro tiempo, la prensa se oponía al poder constituido, por ejemplo con la potente participación de Emile Zolá en el caso Dreyfus. Hoy es la herramienta más enérgica de este núcleo de dominación social. Impone los mecanismos de investigación y su criterio de verdad. Las pruebas siempre "se posponen para más adelante" (Deleuze, 2007, p. 161).

Así también, un último rasgo de las sociedades de control que será analizado, atañe al sistema democrático liberal. Si bien en la ciudad griega la posibilidad del diálogo para exponer opiniones políticas se ejercía sobre la base de ciudadanos libres e iguales. El espacio público ha sido considerado por muchos filósofos defensores de la democracia como un elemento de vital importancia para su verdadero ejercicio. Barbero señala "Lo que emerge en la "esfera pública" es un nuevo modo de asociación no vertical" (Barbero, 2007, p. 46$)^{10}$. Sin embargo, no es posible pensar al individuo como un sujeto con voz y pensamiento propio en el espacio público, puesto que esta voz ya es la resonancia de una serie de operaciones políticas previas ejercidas por mecanismos disciplinarios, gubernamentales y soberanos desde el nacimiento, incluso desde su gestación. El individuo contratante, el sujeto incluso con un velo de ignorancia es un apéndice de la máquina deseante, es un efecto residual de investimentos sociales de deseo ( $D+G, 2007$, p. 284). Los

\footnotetext{
${ }^{10}$ En el espacio público tiene un papel central la deliberación y la acción comunicativa, "se forma una opinión pública política, un espacio público que las personas privadas pueden utilizar como medio de crítica permanente, y que cambia las condiciones de legitimación del poder político" (Habermas, 1987, p. 435).
} 
únicos criterios para la filosofía política deleuziana son de carácter nominalistas, empíricos e inmanentes, y defienden a la democracia como un devenir-activo.

3.2 La democracia como devenir activo. Si bien la historia difiere del devenir, es necesario aclarar la noción de historia a la que se señala. Éste, remite al relato histórico dominante, el cual es de carácter positivista. En referencia a los estudios sobre Foucault, se afirma que sólo el pensar es acto de experimentación, y que la historia positivista se resume a la interpretación, la experimentación es algo que escapa a la historia (Deleuze, 1995, p. 172). La historia positivista tiene como un único objeto al Estado. No obstante, hay elementos que se extienden más allá o más acá del poder estatal. Por encima, hay todo un mercado transnacional, que lucha por sortear las legislaciones impositivas de cada Estado-nación. Por debajo, se mueven los devenires y sus políticas minoritarias (Deleuze, 1995, p. 243). Y es por este motivo, que cuando se cree reprochar la historia de las revoluciones por el hecho de que todas terminan mal -sea, Stalin, Napoléon, Robespierre o Cromwell-, es necesario advertir que frente a esta lectura de la historia hay un devenir revolucionario que permanece intacto. El devenir irrumpe en la historia para transformarla plenamente por medio de fuerzas intempestivas.

Por este motivo, el acontecimiento de mayo del 68 se trata de un devenir revolucionario e intempestivo (Deleuze, 1995, p. 268). Esta relación entre lo intempestivo y lo político es ya señalada [en 1967] en referencia a un supuesto esteticismo despolitizante en la filosofía nietzscheana (Deleuze, 2005b, p. 168). Por el contrario, la emergencia de fuerzas intempestivas no puede ser reducida a un proceso histórico, pero permite hacer coincidir el devenir revolucionario con el acaecimiento de la historia: "cuando un pueblo lucha por su liberación siempre hay una coincidencia de los actos poéticos y los acontecimientos históricos o las acciones políticas, encarnación gloriosa de algo sublime o intempestivo" (Deleuze, 2005b, p. 169). El devenir revolucionario es el direccionamiento de las fuerzas intempestivas contra la vergüenza del conjunto de injusticias que han sido forjadas en la historia material y olvidadas por el discurso histórico dominante. Pero para dar lugar a este acontecimiento intempestivo es necesario creer en el mundo, creer en el potencial de un cambio revolucionario para este mundo (Deleuze, 2005a, p. 227). La dignidad del acontecimiento, la contra-efectuación, creer en el mundo, la vergüenza por la ignominia del tiempo presente, la creación de otro mundo posible: todas estas ideas son de carácter democrático de manera eminente. ${ }^{11}$ En el cine existe la posibilidad de distinguir entre la acción y la imagen puramente sonora y óptica, en esta diferencia el pensamiento logra captar lo intolerable (Deleuze, 2005a, p. 33). La historia positivista del Estado socaba

11 Según plantea Ramos, "un imperativo político: que la ignominia del mundo actual sea el motivo para que nuestra acción individual entre en un devenir impredecible" (Ramos, 2005, p. 291). 
el pensamiento crítico, el devenir democrático sólo es posible al asumir la necesidad de captar lo intolerable de este tiempo presente.

El devenir libera al deseo de su estado de represión, deja atrás los retratos familiares en pos de una expresión musical $(D+G, 1998$, p. 10). El devenir implica un proceso de innovación y experimentación, pero es necesario interrogarse si todo proceso de experimentación y creatividad pueden ser definidos como un acto político (Žukauskaite, 2011, p. 194). Todo devenir es minoritario, pero en qué medida se convierte en acto político. Una minoría no se define por su atribución cuantitativa, sino por su alejamiento respecto de un axioma, el cual configura un espacio de estriación estatal donde sólo es posible la expresión de una mayoría, esto es, de un grupo dominante y su resonancia masiva. El sistema axiomático capitalista sólo maneja conjuntos numerables, pero las minorías se caracterizan por ser conjuntos no-numerables. Es posible que las democracias liberales concedan estatutos de autonomía regional a las minorías, pero con ello, sólo las convierten en un sub-conjunto numerable. Sólo es numerable una etiqueta socialmente aceptada, el propietario, el blanco, el heterosexual, etc. Pero, una minoría desde el punto de vista de la axiomática sólo puede ser definido en términos negativos: el no-blanco, el no-propietario, etc. Una mayoría es una multiplicidad cuantitativa y divisible, mientras que la minoría es una multiplicidad intensiva e indivisible ( $D+G, 2002$, p. 474). En rigor, una minoría corre el peligro de ser axiomatizada, por ello es necesario potenciar el devenirminoritario. No hay devenir mayoritario, esto no puede conducir al rechazo de la democracia, definida esta como el gobierno de las mayorías (Mengue, 2003; Patton, 2005). Todo se trata de hacer estallar las estrías estatales, sus segmentaciones duras, sus aparatos de resonancia. Cómo hacer delirar una lengua mayoritaria e imperialista, cómo introducir en los discursos políticos dominantes, un uso minoritario "para inventar nuevas fuerzas y nuevas armas" (Deleuze y Parnet, 1980, p. 9).

El devenir de una política revulsiva se inicia en el espacio rizomático de las minorías, allí lo privado se mezcla inmediatamente con lo político ( $D+G, 1998$, p. 27), "no hay historia privada que no sea inmediatamente pública, política, popular" (Deleuze, 1996b, p. 91). La escritura política encuentra su potencial de desterritorialización al colmarse del contenido de las injusticias padecidas por desarrapados del mundo. No se escribe para las minorías, sino que a su encuentro, la escritura política alcanza allí su devenir (Deleuze \& Parnet, 1980, p. 53).

Así es que estos procesos de minoriazación tienen tres rasgos sobresalientes: (a) una expresión que hace oír el clamor de las minorías; (b) el devenir-otro de los avocados a esa escucha unívoca del ser; (c) la expansión global de los devenires minoritarios. Tres acontecimientos políticos entendidos como contra-efectuaciones, como una lucha contra la hegemonía cultural burguesa. Resta una última conjunción, allí donde lo minoritario emprende una alianza con el devenir-democrático para convertirse, a su vez, en un 
devenir-revolucionario. Allí también, resurge la utopía como una fabulación. Ésta consiste en promover al devenir-democrático como irrupción de una política revolucionaria que "lleva a su máximo extremo la crítica de su época" ( $D+G, 1995$, p. 101). Marcelo Antonelli (2012) señala que la utopía deleuziana, al encarnarse por el principio de inmanencia, evita toda pretensión de normatividad, el riesgo del autoritarismo. La utopía se vuelve fabuladora cuando logra conectar el entusiasmo del devenir-revolucionario con las luchas contra el capitalismo (Antonelli, 2012, p. 537). Esta crítica fabuladora ${ }^{12}$ no radica en volver a creer simplemente en los principios liberales de justicia y equidad, sino en potenciar las fuerzas afectivas minoritarias, en potenciar las diferencias, en potenciar las multiplicidades. Tales son los principios inmanentes de una fabulación democrática, democratizadora y democratizante. No se abandonan los procesos de liberalización y justicia social, simplemente son criticadas las representaciones liberales de estos principios. No es posible creer aquella política liberal que apela a un futuro sin guerras. Es necesario creer en la democracia como una máquina de guerra que se enfrenta al sistema capitalista entendido como una fábrica de miseria humana (Deleuze, 1995, p. 271).

3.3 Democracia y la máquina de guerra. La máquina de guerra convierte al devenir-democrático en un devenir-revolucionario, puesto que le otorga consistencia a la crítica al dotarla de una innovación en la vida política. La máquina de guerra no busca la batalla (D+G, 2002, p. 415), su estrategia es el ataque relámpago. En rigor, actúa como una guerrilla. La democracia en cuanto irrumpe en el cuerpo del capital lo hace bajo la forma de una guerrilla, esto la convierte en una máquina y en un devenir-revolucionario. La guerrilla convierte a todas las verdaderas fuerzas democráticas en singularidades nómadas que se mueven como en un desierto (Deleuze, 1996, p. 169). Cuando la máquina de guerra se erige en movimiento democrático se convierte en una máquina de guerrilla. "Una máquina de guerra puede ser mucho más revolucionaria o artística que bélica" (Deleuze, 1995, p. 57).

Así pues, la máquina de guerrilla democrática si bien parece que sólo procura una destrucción de segmentos molares referido casi siempre a las grandes instituciones del Estado, en rigor, busca una línea de fuga para hacer huir contenidos que permanecerían estables hacia una nueva territorialidad. Se trata de una expansión intensiva del pensamiento, y de las prácticas políticas democráticas. Es necesario esclarecer cuáles son los rasgos distintos del devenir democrático como máquina de guerrilla. (i) Siempre se trata de un movimiento poblacional que tiene como efecto relevante una transformación de las relaciones jurídicas. (ii) Hay una composición numérica flexible, no jerarquizada, abierta a

\footnotetext{
12 "(...) escribir, hablar, pensar, son actos que pueden llegar a devenir acontecimientos políticos fundamentales, más allá de las teorías del estado y las doctrinas del consenso" (Pellejero, 2007 , p. 156). Por su parte, Antonelli (2017) en un texto más actual desarrolla la noción de "inmanencia práctica" pero la reduce al campo de la ética.
} 
posibles modificaciones. (iii) Hay una articulación o encuentros de afectos ligados a la expresión literaria como devenir-minoritario.

(i) Las irrupciones de la democracia revolucionaria en la historia tiene como manifestación un movimiento de reclamos sociales, toda una serie inventiva de desplantes al poder instituido. En una primera serie conformada por los ejemplos de barricadas en un enfrentamiento campal, o un piquete como método expeditivo para la expresión de una huelga. Se trata no de una ausencia de movimiento, por el contrario, es una composición intensiva de un estallido social, movimiento in situ. Luego es posible analizar otros dos tipos de movimientos democráticos. El primero es el que de hecho realiza una marcha o manifestación multitudinaria itinerante. ${ }^{13} \mathrm{~A}$ estos se agregan los distintos movimientos migratorios, que van desde una periferia hacia un centro de poder económico y político, al cual no dejan de alterar. Un último caso de irrupción intempestiva refiere a la aparición durante la segunda mitad del siglo XX de los distintos movimientos sociales: ecologistas, feministas, pacifistas, anti-globalización, etc. En todos los casos, lo propio de estos procesos es su carácter inventivo y crítico.

(ii) La minoridad sintetiza conjunciones discretas entre distintas minorías comunales, aunque esto no implique una comunicación abierta. En la medida en que son atravesadas por un devenir revolucionario debe haber un lineamiento que todos los grupos puedan aceptar. Es probable que el objetivo general de ese movimiento no tenga el mismo interés para las distintas agrupaciones, pero en alguna medida debe contener algún punto por el cual ellos deseen luchar. Una comunicación abierta implica que cualquier elemento de un grupo puede distribuir información interna hacia cualquier otro elemento externo. Ninguna máquina de guerrilla funciona de esta manera. El sistema de numeración permite analizar las variaciones al interior de cada tribu, su crecimiento o su mortalidad, como tal funciona como un factor de gobernación interna. Pero además, cada grupúsculo tiene una singularidad con la función extraordinaria de comunicarse con las demás tribus. Esta singularidad puede ser llamada "anomal" (D+G, 2002, p. 249). Esta comunicación discreta permite dar consistencia al accionar de la máquina de guerrilla y poner una puesta en común en la contra-efectuación del devenir revolucionario. La mayor eficacia es que cada grupúsculo ataca con una estrategia diferente -horario, intensidad y número diferente-, lo cual impide todo tipo de previsibilidad. Sin tener contacto más que en un mínimo deseable, las minorías ponen en juego un devenir minoritario complejo que tiene un efecto global que supera los intereses grupales, en todos los casos el movimiento revolucionario inyecta el devenir democrático como acontecimiento incorpóreo en medio de los procesos históricos del sistema capitalista. El centelleo de un cometa en mitad de la noche oscura de la

\footnotetext{
${ }^{13}$ Se pueden citar distintos ejemplos, la marcha por el voto femenino en 1917 en EEUU, la marcha de la sal en 1930 en la India, las manifestaciones estudiantiles de Soweto 1976 en Sudáfrica. Incluso la lucha independentista de nuestro país tiene como punto sobresaliente el éxodo jujeño.
} 
Historia. El devenir democrático es una contra-efectuación ya que actúa contra el tiempo presente, contra el status quo dominante, y en favor de un tiempo venidero (Nietzsche, 1999, p. 32).

(iii) La filosofía política deleuziana toma a la máquina de guerra en relación con una noción particular de conocimiento científico, a la que denomina ciencia menor o nómada. Por ejemplo, la historia de la ciencia puede rastrear cómo la física de Demócrito ha sido vituperada por la aristotélica, o la geometría de Arquímedes fue olvidada frente a la de Euclides (D+G, 2002, p. 369). Las ideas de democracia participativa rousseaunianas han quedado eclipsadas frente al equilibrio entre la libertad del sujeto y la obediencia ante el Estado promovida por todo el liberalismo político. No se trata de la astucia de la Razón, sino de una lucha política al interior de la historia del pensamiento. ${ }^{14}$

En cuanto al desarrollo de un pensamiento político que posibilite la expansión de la democracia revolucionaria, en lo que atañe a Deleuze, se puede observar cómo se encuentran fuertes conexiones afectivas con la literatura. El devenir democrático encuentra su potencia de movilización a partir de esta afectividad que entabla con la literatura menor (D+G, 1998, p. 29). No se trata que el autor sea menor, en el sentido de alguien poco conocido o que pertenezca a una minoría étnica, sino simplemente que promueva un pensamiento y una afectividad política revolucionaria en favor de un devenir democrático. ${ }^{15}$

¿En qué sentido la democracia se conecta a una máquina de guerra? En un sentido muy preciso, en la medida en que se contra-efectúa como movimiento externo al Estado. Es irreductible a un aparato estatal, exterior a su poder soberano y previo a su orden jurídico ( $D+G, 2002$, p. 360). La democracia se actualiza como una amenaza externa al sistema capitalista. Si el capitalismo es un sistema axiomático que logra recodificar los flujos desterritorializados y asignarles un encuadre fijo en función de la explotación y dominación del capital, el movimiento democrático no se deja reducir a un axioma de este sistema. Ciertamente, la aparición del liberalismo político logró configurar una representación particular de la democracia. Y para ello, tuvo que concebir primero una forma-pura, una idealidad de existencia democrática, y luego considerar que esta representación liberal es el modo más adecuado para concretar tal formalidad. Sin embargo, el movimiento democrático es una diagramación consistente de multiplicidades singulares, lo propio de esta diagramación es su capacidad de afirmar la diferencia. Por otra parte, es necesario recordar que toda representación consiste en la anulación de las

${ }^{14}$ Es posible observar cómo la teoría republicana clásica defendida en el Discurso sobre Tito Livio ha sido afrentada por las teorías de la soberanía y el contractualismo. Esta cuestión recién en las últimas décadas ha sido recuperada, ver: Pettit, Ph. (1999); Skinner, Q. (2002). Berlin, I. (1998). Mouffe también analiza la cuestión (Mouffe, 1999, p. 41).

${ }^{15}$ Se analiza la fórmula esgrimida por Menville en su Bartleby, el escribiente, como indeterminación que actúa como mecanismo corrosivo frente al poder constituido (Deleuze, 1996, p. 117). En el estudio sobre T. E. Lawrence, advierte las luchas anti-imperialistas y las operaciones bélicas de los partisanos como una máquina de guerrilla nómada (Deleuze, 1996, p. 191). 
singularidades que habitan la diferencia en el devenir activo. En cuanto tal, el devenir democrático y su plano de consistencia no es posible de ser convertido en una generalidad, o en una representación política o en un principio trascendente.

Por su parte, la representación liberal ha tenido una larga historia, ha sufrido diferentes enfrentamientos. Primero, ha luchado contra la imagen de una república en la época renacentista. En función de este desafío, ha excluido las nociones de virtud y libertad positiva, luego ha tenido que agregar el axioma de los procedimientos electorales y con el tiempo, incluir en ese proceso la participación femenina entre otros avatares de su evolución histórica. Más allá de los modos concretos que ha tomado en cada EstadoNación, un punto en común es excluir al "pueblo" de la participación directa en la toma de decisiones políticas. Esto lleva a que amplios sectores de la población no tienen ni voz, ni voto en disposiciones de economía política, en particular, en la organización de los medios de producción capitalista y distribución de la riqueza. Por tal motivo, el significado liberal de "pueblo" remite a una mayoría cuantitativa, pero en rigor, simplemente es una serie de minorías heterogéneas e inconexas que giran en torno al socius del capital.

Frente a todo ello, Deleuze nunca ha rechazado la democracia, pero sí ha sostenido la crítica a su modalidad liberal y capitalista. De manera análoga, Marx y Engels, advertían que el Partido Comunista no impugnaba la institución de propiedad como tal, solamente atacaba a la propiedad privada burguesa de los medios de producción. Asimismo, señalaban que en sus orígenes la Burguesía había cumplido un papel altamente revolucionario (Marx \& Engels, 1998). Este aspecto es el que se puede denominar como momento propiamente democrático al interior del capitalismo. Momento en el cual el movimiento democrático actuó como una máquina de guerra, primero contra el feudalismo y luego contra los regímenes monárquicos y su sistema nobiliario. No obstante, rápidamente los efectos de estas revoluciones han sido recodificados y reterritorializados.

Así pues, el sistema capitalista por sí mismo sólo posee la capacidad de generar desterritorializaciones mortuorias, guiadas por un ánimo necrofílico. Por cierto, cabe preguntarse si el devenir democrático puede generar este tipo de desterritorializaciones sumidas por el instinto de muerte. Existen ejemplos donde máquinas de guerras han promovido enormes y complejas manifestaciones de desterritorialización, pero que por su origen ultraconservador, y raigambre xenófobas generaron la formación de Estados totalitarios, con numerosas recodificaciones. Por un lado, aparecen las experiencias del nazismo y el fascismo, y allí hay que agregar el rebrote de nuevos focos de ultraderecha en toda Europa. Además, se advierte la emergencia de una nueva forma de Estado totalitario, como el Estado Islámico, que mantiene un movimiento nómada incesante, ligados a fuertes reterritorializaciones.

\section{Estado y potencia de la minoría.}


La incorporación de nuevos derechos socio-políticos es evidencia de movimientos democráticos de desterritorialización generados por la máquina de guerra que atraviesa el campo inmanente del sistema capitalista y produce todo una revolución molecular. Deleuze y Guattari nunca han rechazado estos triunfos en el campo del sistema jurídico $(D+G, 2002$, p. 474). El énfasis está dirigido a demostrar que este movimiento no es resultado del progreso material orientado por el sistema económico vigente, sino por el contrario debe ser entendido como una involución creadora $(D+G, 2002$, p. 167), opuesto a la organización capitalista. No obstante, en todos los casos, deja de tener la fuerza propia de una máquina de guerra nómada, ya que sus innovaciones están sujetas a sufrir todo tipo de reestructuraciones axiomáticas.

¿Es posible crear mecanismos de integración que no coarten las autonomías de las asociaciones minoritarias? ¿Esta transformación del Estado de qué naturaleza puede llegar a ser? Ernesto Laclau frente a un espontaneísmo ${ }^{16}$ de la multitud como agente de la sublevación, cuestiona que la articulación emerja como una convergencia de orden "natural". Ésta se legitimaría por el hecho de oponerse "contra todos en todas partes" (...), se trataría de una "unidad caída del cielo" (Laclau, 2005, p. 299). En cambio, su teoría postula una articulación hegemónica, donde un líder logra clarificar los reclamos de distintas sectores, incluso cuando estos aun no son conscientes de ello. Esta articulación viene a instanciar a los significantes vacíos. ${ }^{17}$

Ahora bien, la crítica de Laclau se dirige contra el inmanentismo radical de Hardt y Negri, ¿qué sucede al respecto en la política deleuziana? Deleuze y Guattari rechazan ambas posturas, tanto el esponteneísmo como el liderazgo hegemónico-populista. Guattari es más enérgico en este caso, respecto a la participación de los grupos minoritarios en un proceso de mutación social generalizado, responde que no hay que negarse a esa tentativa por miedo "en nombre del culto al espontaneísmo" (Guatarri \& Rolnik, 2013, p. 228). El Estado centralizado debe respetar las autonomías, pero ¿es posible la convivencia entre los partidos políticos y estos devenires minoritarios? Es necesario que la experimentación evite dos polos negativos, la recaída en una burocratización y microfascismo por un lado, y si se aíslan demasiados se recae en una degeneración del sectarismo. Ejemplos de este proceso pueden ser la Gauche Proletarienne en Francia, o las Brigadas Rojas en Italia (Guatarri \& Rolnik, 2013, p. 236). Para Guattari se trata de dos

\footnotetext{
${ }^{16}$ Chantal Mouffe coincide en esta crítica "Estas luchas no convergen espontáneamente, y a fin de establecerlas equivalencias democráticas se necesita un nuevo "sentido común» que transforme la identidad de diferentes grupos" (Mouffe, 1999, p. 39).

${ }_{17}$ Se rechaza la teoría de Laclau por dos motivos: (1) las articulaciones no pueden depender de una lógica de equivalencias (Laclau, 2005, p. 99) ya que ésta deriva del proceso dialéctico que provoca repeticiones donde se anula las diferencias; (2) la producción de significantes vacíos comprenden al deseo como una negatividad, como una cosa que falta, que busca la satisfacción; en cambio, para Deleuze el deseo es pura positividad y lo que se debe analizar son sus conexiones.
} 
dimensiones independientes, pero que deben tener una co-existencia. ${ }^{18}$ Para Deleuze, el movimiento de las minorías difícilmente pueda tener una expresión clara en las políticas de Estado, y esto ocurre porque el devenir-minoritario rechaza la axiomática capitalista. ${ }^{19}$ Los reclamos de estos sectores de ser afirmados en su positividad, sólo así la minoría logra el devenir universal "devenir todo el mundo" (D+G, 2002, p. 474). La potencia de las minorías no se debe medir por su capacidad de insertarse en las luchas globales, de los partidos y Estados, sino por alterar el sentido del sistema axiomático en la configuración de conjuntos numerables.

Si bien es cierto que "El Estado vive y se alimenta de las prácticas y formas de las multitudes deseantes" (Arcos, 2016, p. 96). La potenciación de la máquina de guerra no se logra sólo por rechazar al Estado como aparato de captura porque, con las políticas neoliberales, la axiomática también genera una sustracción de axioma, y esto se materializa en un estado mínimo de tipo anarco-capitalista tal como ocurría en la dictadura de Chile en la década de los 80 ( $D+G, 2002$, p. 467). Lo que se rechaza del Estado de bienestar keynesiano es que sólo se aplique a la proliferación de axioma para el equilibrio del sistema social dominante. En ambos casos - en el Estado neoliberal o en el benefactor- se promueve una subjetividad capitalista. Es necesario deconstruir la función infantilizadora del Estado-Providencia (Guatarri \& Rolnik, 2013, p. 211). El problema no es elegir entre anarquismo o centralismo, ${ }^{20}$ sino de cómo construir el devenir de las minorías en un plan de inmanencia. ${ }^{21}$ Se rechaza el plan de exterminio del totalitarismo, como el plan de integración de capitalismo. La inmanencia es resultado de la construcción política, que implica la articulación de la lucha global al nivel macro-político y la revolución molecular.

\section{Conclusiones}

\footnotetext{
${ }^{18}$ Es necesario derrumbar aquello que aplasta las singularidades, pero en ese intento no se debe crear instrumentos que aplasten las singularidades, sino "se iría contra el propio deseo de lucha" (Guatarri\&Rolnik, 2013: 229). "Es importantes interrogar a las organizaciones políticas en función de las cuestiones del deseo; (...) interrogar la economía de deseo, en función de las máquinas estatales" (Guatarri \& Rolnik, 2013, p. 239).

19 "Poco importa que las minorías sean incapaces de constituir Estados viables desde el punto de vista de la axiomática y del mercado, puesto que a largo plazo promueven composiciones que ya no pasan por la economía capitalista ni por la forma-Estado" (D+G, 2002, p. 473).

${ }^{20}$ Daniel Bensaid (2010) analiza la postura de J. Rancière (1998), para este último, no debe confundirse la democracia participativa con un exceso de democracia, y cita a este autor: "No se trata de desacreditar el principio de la organización en beneficio de una valorización exclusiva de las escenas explosivas. Mi propuesta se posiciona por fuera de toda polémica u oposición organización contra espontaneidad" (Bensaid, 2010: 35).

${ }^{21} \mathrm{Al}$ respecto, "el de un cálculo o concepción de los problemas relativos a los conjuntos no numerables frente a una axiomática de los conjuntos numerables. Pues bien, este cálculo puede tener sus composiciones, sus organizaciones, incluso sus centralizaciones, pero no pasa por la vía de los Estados ni por los procesos de la axiomática, sino por un devenir de las minorías" (D+G, 2002, p. 474).
} 
¿En qué consiste el fracaso de las democracias liberales? (i) En impedir el acceso irrestricto a todos los ciudadanos en la toma de decisiones respecto al modo de producción y reparto de la riqueza generada. (ii) En crear y propagar enormes niveles de injusticia social. (iii) En ponderar los principios de igualdad y libertad como principios normativos trascendentales. (iv) En configurar a la opinión pública como un plano doxográfico. La representación liberal en su conexión con la axiomática capitalista se caracteriza por generar herramientas políticas que obstaculizan la potenciación de las fuerzas creativas.

La democracia es un rizoma, esto significa que es un agenciamiento colectivo de enunciado y que en su expresividad se distingue de las representaciones liberales afianzadas por la dominación capitalista. En tanto que rizoma se afirma como una nueva imagen del pensamiento político, esta es una imagen intempestiva de la escritura política. Esta textualidad remite a toda manifestación del sentido y del acontecimiento político. Entonces se liga la innovación, la creatividad y la experimentación de nuevas formas expresivas. Éstas sostienen una crítica frente a los discursos dominantes y sus aparatos de resonancia. A la vez, construyen un plano de consistencia. Allí las políticas democráticas se manifiestan por medio de instituciones entendidas como modelos de acción que promueven una revolución permanente.

La multiplicidad sólo puede ser comprendida como pueblo en cuanto acontecimiento político que despliega una diferencia intensiva y se expresa en el encuentro de afecciones positivas, que genera un aumento de las potencias de las singularidades involucradas. Se ha criticado el supuesto de Philippe Mengue (2007) de pensar el concepto "pueblo que falta" como una definición puramente negativa y enraizada en un cierto esteticismo. Si bien la literatura menor le permite a Deleuze acerca a este concepto, su función es promover la creación de líneas de fuga y el empoderamiento de los grupos socio-culturales minoritarios.

Asimismo se rechaza la idea a la democracia como ámbito doxográfico donde se asegure la libertad y la igualdad en la expresión de acciones y opiniones. La razón de esta postura se debe a que los medios de comunicación -predominantemente privados- ya han manipulado la opinión pública en favor de los intereses concentrados. Estos aparatos de resonancia han creado un sentido común y un buen sentido como contenido del hombre unidimensional. $Y$ estos individuos que pretenden expresarse libremente son aquellos que han sido forjados por una serie de micro-poderes disciplinarios y otra serie de dispositivos de seguridad gubernamental. El plano doxográfico es un espacio de estriación estatal, y por ello, dirigir la crítica filosófica contra el sentido común no convierte a la filosofía deleuziana en anti-democrática, por el contrario, hace visible las fisuras del sistema por donde podrán estallar las líneas de fuga. ${ }^{22}$

\footnotetext{
${ }^{22}$ La opinión pública no surge de una operación ideológica consistente en ocultar una verdad o un verdadero sentido del mundo. Los medios dejan hablar al individuo normalizado, que ha introyectado un contenido discursivo forjado ya en una lucha política previa.
} 
Además, se ha analizado el postulado de un devenir-democrático fundado en un sistema normativo. El riesgo es un retorno a principios trascendentes. A lo que se agrega al debate y justificación, sus decisiones basadas en una cultura política. Para la filosofía platónica este principio democrático genera una gran dificultad, ${ }^{23}$ dado que el debate y los arbitrajes pueden surgir al fragor de largas reyertas conducentes al sin sentido. La creatividad platónica ha consistido en postular la noción "Idea" como aparato conceptual para garantizar un contenido científico (episteme) como verdadero y sus derivaciones políticas como las únicas que puedan ser valoradas como legítimas $(D+G, 1995, p .15)$. Es probable que este acontecimiento histórico haya alejado a la filosofía del pensamiento democrático. Si bien la postura antidemocrática de Nietzsche resulta coincidente con Platón, la filosofía política deleuziana rechaza ambos sistemas argumentativos.

Frente a ello, se defiende al devenir como una experimentación que no contiene ninguna certeza previa. $\mathrm{Y}$ sin embargo, no es posible siquiera pensar a esta incertidumbre como elemento estructural antropológico, ni como un rasgo de la condición humana. Simplemente es el resultante de un empirismo radical, que nos advierte que la democracia liberal está comprometida "hasta la saciedad en esta fabricación de miseria humana" (Deleuze, 1995, p. 271).

La democracia actúa como contra-efectuación, y se define como un elemento externo al sistema capitalista, que sólo ha sido axiomatizado bajo la forma representativa liberal. No obstante, el devenir-democrático se actualiza como una máquina de guerrilla contra el sistema capitalista. Genera movimientos poblacionales de resistencia al poder instituido, crea composiciones numéricas, no jerarquizadas y abiertas, con una comunicación discreta en conexión a partir de una singularidad anomal. A este nomadismo se agrega los encuentros afectivos ligados a la expresión literaria como devenir minoritario. En tanto que máquina de guerrilla su función es generar una desterritorialización, hacer estallar las fisuras de los bloques históricos que conforman las segmentaciones molares de los grandes aparatos estatales. Pero además, en su definición positiva esta desterritorialización tiene por objeto crear y crear en una nueva tierra y en un nuevo pueblo.

La creatividad filosófica promueve el devenir democrático en la medida que visibiliza la otredad política. Se trata de un conjunto heterogéneo de devenires minoritarios que expresan una multiplicidad de voces -asimétricas, divergentes y plurales-. Estos a su vez, se mueven sobre el plano de la univocidad del ser. Estas voces expresan su clamor democrático.

El clamor del ser es la denuncia que nace de la vergüenza de no soportar ser parte del sistema opresivo, denuncia frente a las calamidades que padecen los condenados de la tierra. Ese clamor es una minorización de la lengua imperialista, un devenir otro de la lengua. Sentirse afectado por esas calamidades ya "es un afecto asociado con un proceso

\footnotetext{
${ }^{23}$ Alain Badiou analiza esta cuestión, la convicción de Platón es "que la democracia no salvará a la ciudad griega." (Badiou, 2010: 17). Sólo está ligada a la satisfacción de los placeres juveniles.
} 
de devenir-otro" (Patton, 2013, p. 113). En el devenir minoritario hay diversas síntesis conjuntivas de flujos intensivos que permite tejer una red "para todos los devenires minoritarios del mundo" (Deleuze y Parnet, 1980, p. 59). Allí también, la filosofía encuentra su vocación política, crear conceptos para iniciar un acontecimiento revolucionario. Tomar los flujos que fueron fijados por la axiomática capitalista y reimpulsar su desterritorialización absoluta ( $D+G, 1995$, p. 101). Se vuelve a creer en este mundo en la medida en que se apela a una nueva tierra y a crear un pueblo que falta.

\section{Referencias bibliográficas}

AAVV. (2010). Democracia ¿̇en qué Estado? Giorgio Agamben; Alain Badiou; Daniel Bensakl. Buenos Aires: Prometeo.

Antonelli, M. (2012). El problema de la utopía en Gilles Deleuze. Isegoría, (47), 519-539.

Antonelli, M. S. (2017). El concepto de "inmanencia práctica" en Deleuze. Ideas y valores: Revista Colombiana de Filosofía, 66(164), 317-341.

Antonioli, M., Chardel, P. A., \& Regnauld, H. (2007). Gilles Deleuze, Félix Guattari et le politique. Paris: Sandre.

Arcos Fuentes, I. (2016). El Leviatán como aparato de captura: una perspectiva materialista sobre la forma Estado desde Marx, Althusser, Foucault y Deleuze. Inguruak, (60).

Arendt, H., (1993). La condición humana, Barcelona: Paidós.

Barbero, M. J. (2007). Transformaciones comunicativas y tecnológicas de lo público. Metapolítica, 5 (17), 46-55.

Benjamin, W. (1989). Discursos interrumpidos I, Filosofía del arte y la historia (Trad. J. Aguirre).

Buenos Aires: Taurus-Alfaguara.

Berlin, I. (1998). "Two concepts of liberty». The proper study of mankind. Nueva York: Ferrar, Strauss and Giroux.

Burroughs, W. (1984). Yonqui (Trad. M. Lendínez). Barcelona: Editorial Bruguera.

Cicerón, M. T. (1992). Sobre la República. Sobre las Leyes. Madrid: Tecnos.

Deleuze, G. (1977). Empirismo y subjetividad (Trad. H. Acevedo). Barcelona: Gedisa.

Deleuze, G. (1998). Nietzsche y la filosofía. Barcelona: Anagrama.

Deleuze, G. (2001a). Presentación de Sacher-Masoch. Lo frío y lo cruel. Buenos Aires: Amorrortu.

Deleuze, G. (2006). Diferencia y repetición. Buenos Aires. Amorrortu.

Deleuze, G. (1996a). Spinoza y el problema de la expresión. Barcelona: Muchnik.

Deleuze, G. (1994). La lógica del sentido. Barcelona: Planeta-De Agostini.

Deleuze, G. (2001b). Spinoza: filosofía práctica (Trad. A. Escotado). Barcelona: Tusquets.

Deleuze, G. (2005a). La imagen-tiempo. Estudios sobre cine 2. Buenos Aires: Paidós.

Deleuze, G. (1987). Foucault. Barcelona: Paidós.

Deleuze, G. (1995b). Conversaciones. Valencia: Pre-Textos. 
Deleuze, G. (1996b). Crítica y Clínica (Trad. T. Kauf). Barcelona: Anagrama.

Deleuze, G. (2005b). La isla desierta y otros textos. Textos y entrevistas (1953-1974). Valencia: PreTextos.

Deleuze, G. (2007). Dos regímenes de locos. Textos y entrevistas (1975-1995). Valencia: PreTextos.

Deleuze, G. (2012). [1987] “¿Qué es el Acto de Creación? ¿Qué es Tener una Idea en Cine?” (Trad. B. Prezioso). Conferencia para la Fundación FEMIS. Dur. 47’. Revista Fermentario, 2012.

Deleuze, G. y Parnet, C. (1980). Diálogos. Valencia: Pre-textos.

Deleuze, G. y Guattari, F. (2007). El Antiedipo. Capitalismo y esquizofrenia. Buenos Aires: Paidós.

Deleuze, G. y Guattari, F. (1998). Kafka. Por una literatura menor. México: Era.

Deleuze, G. y Guattari, F. (2002). Mil Mesetas. Capitalismo y esquizofrenia. Valencia: Pre-textos.

Deleuze, G. y Guattari, F. (1995). ¿Qué es la filosofía? Barcelona: Anagrama.

D’ors A. (1992). Introducción. En Cicerón, M. T. Sobre la República. Madrid: Tecnos.

Ezquerra Gómez, J. E. (2009). Polis y Caos. El espacio de lo político. Revista Res publica, 21, 21-37.

Habermas, J. (1987). Teoría de la acción comunicativa: racionalidad de la acción y racionalización social. Vols. I. Madrid: Taurus.

Hallward, P. (2006). Out of this World: Deleuze and the Philosophy of Creation. Verso.

Laclau, E. (2005). La razón populista. Buenos Aires: FCE.

Marx, K., \& Engels, F. (1998). Manifiesto del partido comunista (Trad. E. Grau Biosca y L. Mames). Barcelona: Crítica.

Mengue, Ph. (2003). Deleuze et la question de la démocratie. Editions L'Harmattan.

Mengue, Ph. (2007). Le Peuple qui manque et le trou de la démocratie. Antonioli, M. (comp.)

Deleuze, Guattari et le politique. Paris: Editions du Sandre.

Mengue, Ph. (2008a). Deleuze o el sistema de lo múltiple. Buenos Aires: Las Cuarenta.

Mengue, Ph. (2008b). People and fabulation. Deleuze and politics (pp. 218-239). Edinburgh: Edinburgh University Press.

Negri, A., y Hardt, M. (2004). Multitud. Guerra y democracia en la era del Imperio. Argentina: Editorial Debate.

Nietzsche, F. (1999). Sobre la utilidad y el abuso de la historia para la vida. Madrid: Biblioteca Nueva.

Patton, P. (2005). Deleuze and democracy. Contemporary Political Theory, 4(4), 400-413.

Patton, P. (2007). Political normativity and poststructuralism: The case of Gilles Deleuze. In Papeer presented at the Vortragins Instituts colloquium des Philosophischen Instituts der Freien Universität, Berlin, am Donnerstag (Vol. 15). Recuperado de: http://deleuze.tausendplateaus.de/wp-content/uploads/2008/01/political-normativity-deleuze.pdf Patton, P. (2008). Becoming-democratic. Deleuze and politics (pp. 178-195). Edinburgh: Edinburgh University Press.

Patton, P. (2010). Deleuzian concepts: Philosophy, colonization, politics. Stanford: Stanford University Press. 
Patton, P. (2013). Deleuze y lo político. Buenos Aires: Prometeo.

Pellejero, E. (2007). ¿Qué es la literatura? Del compromiso sartreano a la fabulación deleuziana. Devenires, VIII (15), 155-177.

Pettit, Ph. (1999). Republicanismo. Barcelona: Paidós.

Protevi, J. (2009). Geohistory and Hydro-Bio-Politics. Deleuze and History, pp. 92-102.

Edinburgh: Edinburgh University Press.

San Agustín (1965). La Ciudad de Dios (Trad. J. Morán). Obras de San Agustín (T. XVII). Madrid: BAC.

Spinoza, B. D. (1986). Tratado político (Trad. A. Domínguez). Madrid: Alianza.

Skinner, Q. (2002). The idea of negative liberty: Machiavellian and modern perspectives.

En Visions of politics II, 186-212.

Yamauchi Terukina, J. L. (2017). Imperio de la Virtud. Balbuena, B. Grandeza Mexicana. Goodbridge: Tamesis.

Zizek, S. (2006). Órganos sin cuerpo: sobre Deleuze y consecuencias. España: Pre-Textos.

Žukauskaite, A. (2011). Ethics between Particularity and Universality. In Deleuze and Ethics (pp. 188-206). Edinburgh: Edinburgh University Press. 